\title{
COSMOCOCAS E SEUS TEXTOS-INSTRUÇÕES: GLOSSÁRIO PARA UM CINEMA EXPANDIDO
}

Ana Gabriela Dickstein Roiffe é doutoranda em Literatura, Cultura e Contemporaneidade na PUC-RIO. E-mail: anadickstein@gmail.com

\begin{abstract}
Resumo
O cinema influenciou a escrita de Hélio Oiticica, na elaboração de algumas obras e reflexões críticas. O artigo analisará de que forma os textos criados para Cosmococas (1973), especialmente a partir do uso de determinados termos, reforçam a proposição de um pensamento sobre o cinema para além de sua forma-espetáculo, a partir da corporalidade ativa dos participantes, do espaço tridimensional e da ruptura com a sequencialidade temporal.
\end{abstract}

\begin{abstract}
Resumen
El cine influyó en la escritura de Hélio Oiticica, sea para la preparación de algunas obras o para sus reflexiones críticas. En este artículo se examinará cómo los textos creados para Cosmococas (1973), sobre todo el uso de ciertos términos, refuerzan su pensamiento sobre el cine más allá de su forma como espectáculo, a partir de la corporeidad activa de los participantes, del espacio tridimensional y de la ruptura con la secuencialidad temporal.
\end{abstract}

A intensa relação de Hélio Oiticica com o cinema nos anos 60 e 70 influenciou grande parte de sua criação artística, no que se inclui uma compulsiva atividade escrita, na forma de reflexões críticas, textos para a montagem de obras, colagens e citações. A voracidade de seus textos revela o empoderamento do artista como escritor e evidencia a profusão de estímulos aos quais estava exposto naquele momento. Como num movimento de retroalimentação, as propostas de cinema expandido mostraram-se uma importante referência para Oiticica, ao mesmo tempo em que, a partir de uma construção vigorosa de pensamentos, formas e termos, o artista-escritor criou conceitos próprios para a construção da sua ideia particular de cinema.

As vias pelas quais Oiticica experimentou o cinema foram diversas. Participou como ator, cenógrafo e/ou homenageado de filmes como $O$ demiurgo (1970), de Jorge Mautner, Câncer (1972), de Glauber Rocha, Lágrima pantera (1972), de Júlio Bressane, H.O. (1979), de Ivan Cardoso, Uma Vez Flamengo (1980), de Ricardo Solberg. Aproveitou os tempos em que viveu em Londres para intensificar sua condição de cinéfilo crônico. E, durante sua estada em Nova York, deixou-se fascinar por artistas como Andy Warhol e Jack Smith, entre outros cineastas experimentais, que ajudaram a dar forma a suas reflexões sobre o pensamento cinematográfico. Disso resultou uma criação prolífica e diversificada, em que a experimentação dos novos diálogos do cinema atuou como norteadora das suas obras em super-8 (Brasil Jorge e Agripina é Roma-Manhattan, ambos de 1972) ${ }^{1}$, cinema expandido (Neyrótica, de 1973, e Helena inventa Ângela Maria, de 1975) e experiências nunca finalizadas (Nitrobenzol \& Black Linoleum ${ }^{2}$ e Norma Inventa La Benguell).

\footnotetext{
${ }^{1}$ Cabe aqui incluir também as experimentações com os irmãos Andreas e Thomas Valentim, que pequenos filmes em super-8, como Phone (1976), Rio de Janeiro 1974-1976 (1976) e Flit (1976).

${ }^{2}$ Segundo Beatriz Queiroz (2013), foi a partir do roteiro de Nitrobenzol \& Black Linoleum que Oiticica começou a pensar em um cinema não-narrativo e ambiental. Escrito por Oiticica em Londres, no ano de 1969, o trabalho consistia de 11 ideias, que orientavam projeções simultâneas em três telas, com trechos que se voltavam para a plateia. A pesquisadora destaca a importância que a participação do público representou na construção desses textos.
} 
Algumas dessas obras formaram parte do projeto de quasi-cinemas, desenvolvido em 1973 por Oiticica e Neville d'Almeida, a partir de inquietações que tiveram em Bloco de experiências in Cosmococa-program in progress, seu resultado mais representativo. Embora nove blocos tenham sido concebidos (com maior ou menor detalhamento), apenas os cinco primeiros foram montados ${ }^{3}$, justamente aqueles em parceria com Neville. Embora as experiências propostas fossem bastante diferentes, a ideia de cada um desses blocos-experiências, como eram chamados, consistia de alguns elementos centrais: o uso de slides, cuja ordem de projeção era parcialmente atribuída ao acaso; uma trilha sonora heterogênea, que serviria como sugestão para a dança e o corpo, o que fez coexistirem numa mesma obra sons da rua, Luís Gonzaga e Jimmy Hendrix, por exemplo; e os jogos-performance, que continham instruções para performances privadas ou públicas, onde havia objetos para interação (como instrumentos para o consumo de cocaína, bolas, cubos de espuma, uma piscina) e direcionamentos para os participantes (como brincar, pular e tirar os sapatos). A concepção do projeto incluía também o conceito de mancoquilagens, criado por Neville d'Almeida. Esse termo combinava as ideias de cocaína e maquiagem, para designar a intervenção que era feita nas imagens dos slides, em que ícones como Luís Buñuel, Yoko Ono, Marilyn Monroe e Jimmy Hendrix tinham seus rostos modificados por linhas de pó branco. Finalmente, os blocos ganharam uma abreviação (CC) e uma numeração, criadas com a intenção de expor o caráter aberto do projeto, cuja ideia era dar continuidade à geração das obras. ${ }^{4}$

\footnotetext{
${ }^{3}$ Os cinco primeiros blocos-experiências só foram montados em conjunto, pela primeira vez, em 2005, no Centro de Artes Hélio Oiticica, no Rio de Janeiro.

${ }^{4}$ Como o objetivo deste artigo é analisar a escrita das Cosmococas, e não as obras montadas, preferi não me estender na descrição de cada um dos blocos-experiências. Para melhor detalhamento, entre os inúmeros livros e teses sobre Oiticica, recomendo Hélio Oiticica \& Neville d'Almeida: Cosmococas, de Max Jorge Hinderer Cruz e Sabeth Buchmann (Rio de Janeiro: Azougue, 2014). 

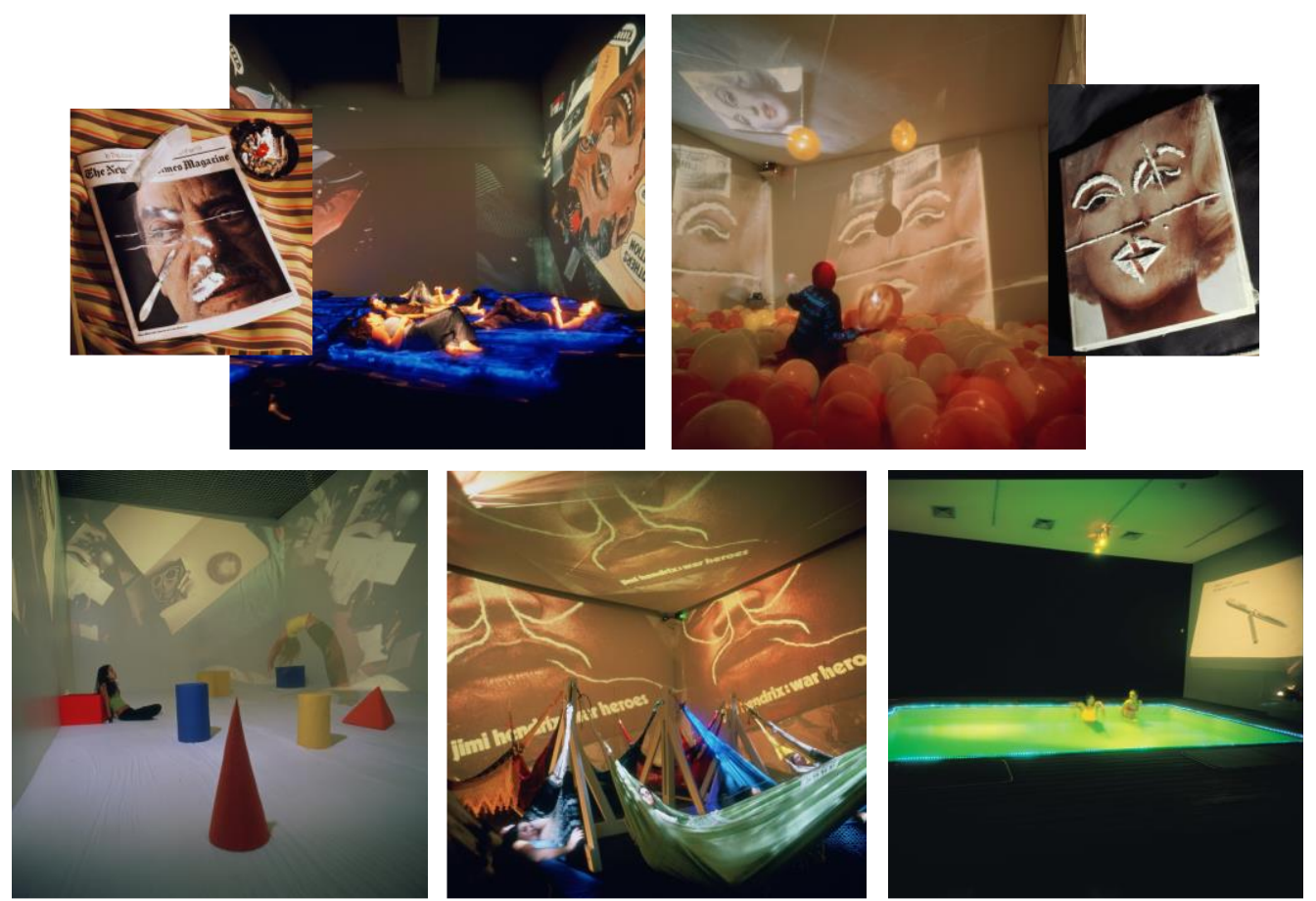

Imagens dos cinco blocos-experiências das Cosmococas que foram efetivamente montados 5

É nesse momento também que o artista passa a desenvolver a escrita como um importante processo criativo, dedicando aos textos grande parte do seu tempo. Com o objetivo de reunir toda a sua produção no livro Newyorkaises ${ }^{6}$, Oiticica escreveu inúmeros cadernos, aos quais numerava e abreviava como "NTBK" (notebook), com anotações manuscritas e datilografadas, em inglês e português, e páginas de colagens.

Incorporado posteriormente como uma das partes dessa publicação, o projeto Cosmococas foi escrito em dois cadernos (NTBK 1/73, que se iniciou em 22/06/1973, e NTBK 2/73, de 27/10/1973), que ilustram a maneira como sua escrita adota a ideia de cinema, tanto na sua abordagem temática, como no uso de técnicas associadas ao cinematográfico. Nessas páginas, que atestam a complexidade de sua escrita, o artistaescritor construiu diferentes camadas, onde reuniu importantes referências para o seu processo criativo, exercitou sua verborrágica opinião sobre temas diversos, com destaque para o cinema, e gerou a base para a realização dos blocos-experiências. Nos cadernos, essas camadas nem sempre são claramente distinguíveis, seja porque em meio a páginas contínuas de texto encontra-se uma folha com uma única ilustração, ou ainda porque um mesmo texto mescla variadas estruturas. Para este artigo, três camadas foram diferenciadas, de acordo com a sugestiva semelhança que apresentam com relação a determinados formatos de texto, o que funcionará mais como um estímulo à reflexão do

\footnotetext{
${ }^{5} \mathrm{Na}$ linha acima, da esquerda para a direita, $\mathrm{CC} 1$ Trashiscapes (com destaque para a mancoquilagem sobre imagem de Buñuel) e CC3 Maileryn (mancoquilagem sobre fotografia de Marilyn Monroe). Abaixo, CC2 Onobject, CC5 Hendrix-War e CC4 Nocagions.

${ }^{6}$ Projeto que só se concretizou em 2013, com a publicação do livro Conglomerado Newyorkaises, organizado por Cesar Oiticica Filho e Frederico Coelho e publicado pela Azougue Editorial (Rio de Janeiro).
} 
que como uma tentativa de determinar limites nesses textos, cuja inventividade está justamente nos seus movimentos de confluência e indeterminação.

\section{Texto-poema: o plágio como algo atuante}

ideas for a scriptotal

no-script spoken script

despeakable.

C'est le repos éclairé, ni fièvre ni langueur, sur le lit ou sur le pré.

C'est l'ami ni ardent ni faible. L'ami.

C'est l'aimée ni tourmentante ni tourmentée. L'aimée.

L'air et le monde point cherchés. La vie.

- Etait-ce donc ceci?

— Et le rêve fraîchit.

All the somethings in the world begin to sense their at-one-ness when something happens that reminds them of nothing way the music so that its all of the things.

As the boat anchored at Corinth, the quality of Greek light suddenly revealed itself. Water can be transparent anywhere; but here the sun had a power of penetration which transfigured even the bronze tone of the boat's screw. Greece was explained to us by light, materials, and the perfect realization of visualized form.

The individual is something quite new which creates new things, something absolute; all his acts are entirely his own. Ultimately, the individual derives the values of his acts from himself; because he has to interpret in a quite individual way even the words he has inherited. His interpretation of a formula at least is personal, even if he does not create a formula: as an interpreter he is still creative. ${ }^{7}$

Escrever é sempre reescrever, não difere de citar. É assim, pela citação e pela apropriação, que Oiticica personifica a teoria de Antoine Compagnon (1996), ao fazer da escrita, como aponta o autor, uma forma derivada e transitória do recorte e da colagem, da experiência concreta e arcaica com o papel, relacionando-se com a citação como uma prática primordial, formativa, do texto escriptível, do perpétuo desejo de reescrita. Entre John Cage e Rimbaud, passando por Gauguin, Nietzsche, Moholy-Nagy e Toureau, há páginas de Cosmococas que, reunidas, formam um mosaico de citações e apropriações, com folhas coloridas, enxertos de textos sobre fotografias, colagens de trechos sobre outros trechos e ilustrações. A Grécia, a tragédia, o indivíduo, a pintura, o exílio, a música fazem parte da constelação de Oiticica, na construção de uma forma fronteiriça e fragmentada. No recorte e cola, seu poema em construção.

\footnotetext{
${ }^{7}$ Textos do caderno Cosmococas (em ordem descendente), com partes de: escritas de Hélio Oiticica para o caderno; Illuminations (1886), de Rimbaud; Silence: lectures and writings (1961), de John Cage; Moholy-Nagy: Experiment in Totality (1950), de Sibyl Moholy-Nagy; The will to power (1901), de Nietzsche. (OITICICA, Tombo: 0299/73). 

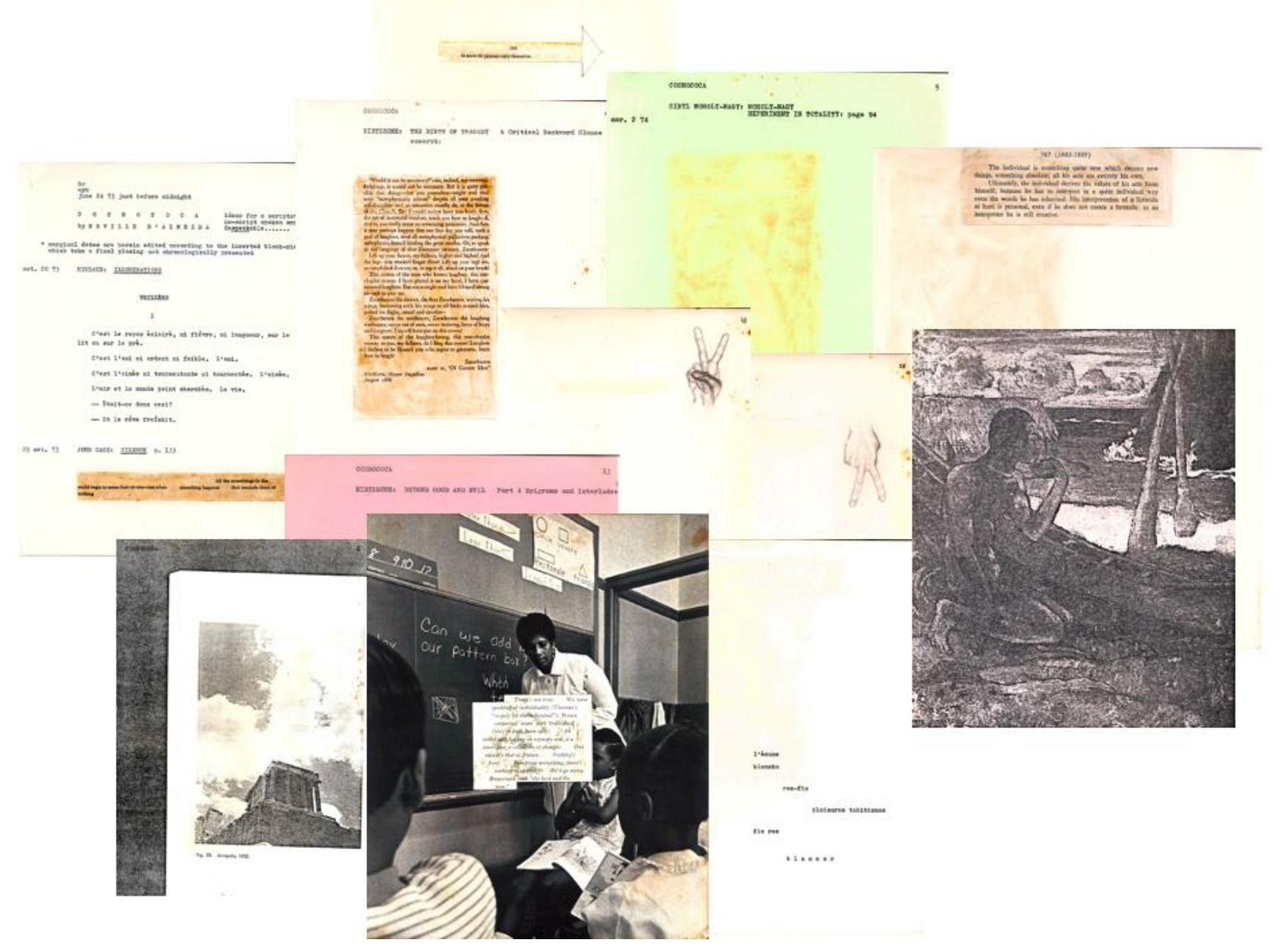

Oiticica copiou trechos de livros, fragmentos de textos e imagens de outros autores nos cadernos das Cosmococas

A pausa. Uma inesperada imagem interrompe a eletricidade inquieta dessa escrita: é "Lü, o viajante", o hexagrama número 56 do I Ching. Usado como método de composição não-intencional por John $\mathrm{Cage}^{8}$, um dos mestres de Oiticica, o livro das mutações chinês é aqui jogo e silêncio, oráculo de uma escrita em exaustoconstrução. A pausa como citação. ${ }^{9}$

\footnotetext{
${ }^{8}$ John Cage começou a usar o I Ching em Imaginary Landscape 4 (1951) e Music of Changes (1951) e passou a adotar o método, ligado a operações com o uso do acaso, ao longo de toda a sua vida.

${ }^{9}$ Marjorie Perloff (2013, p. 48) lembra que, se a citacionalidade ("com sua dialética de remoção e enxerto, disjunção e conjunção, sua interpenetração de origem e destruição”) é central para a poética do século 21 , ainda resiste uma demanda por originalidade no mundo da poesia. Por outro lado, as artes visuais se aproveitam há muitas décadas da apropriação, da citação, da cópia e da reprodução, a exemplo das obras de Duchamp, Christian Boltanski e Cindy Sherman. É nesse sentido que a construção de uma poética de apropriação no caso de Oiticica revela-se não apenas por sua relação com Cage e os irmãos Campos (em especial Galáxias (1984), de Haroldo de Campos), mas também por essa relação ferramental do artista com o construtivismo e a bricolage.
} 


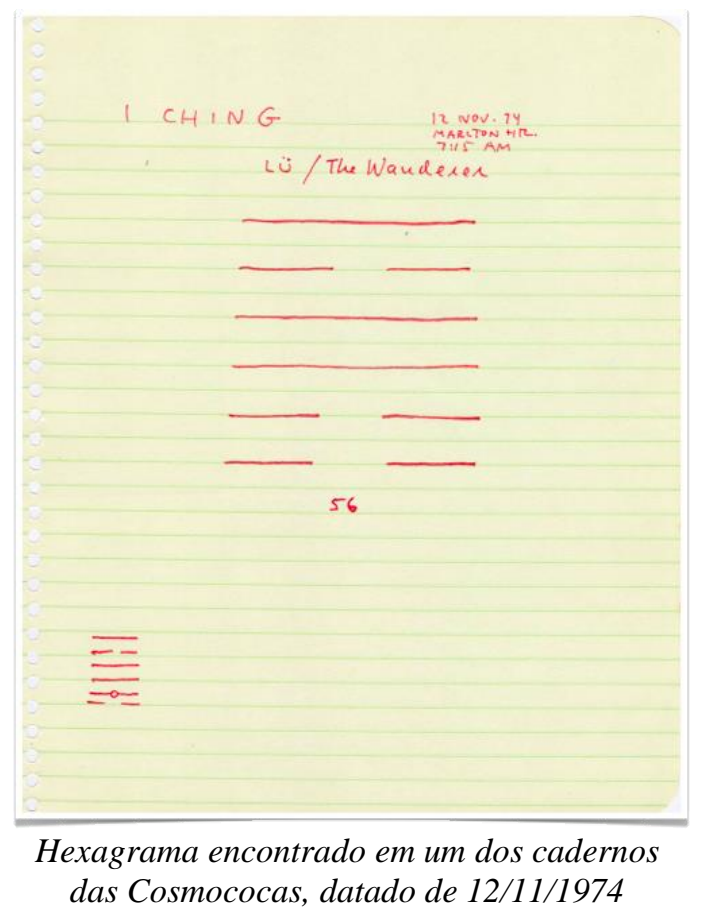

\section{Texto-ensaio: ventilação de discussões}

"Passar a limpo" é um termo em desuso no mundo dos softwares de texto. Mas essa atividade de carpintaria tomou horas de Oiticica na difícil tarefa de transportar, através de uma máquina de escrever, todo o complexo estilo e a extensiva quantidade de material que havia desenvolvido em seus cadernos, com o uso de setas, caixas altas, parágrafos recuados, reticências, hifens, numa relação impulsiva e pretensiosa com a folha de papel. Em páginas com grandes blocos de texto corrido, o artista-escritor atravessa a folha translúcida com a inscrição profunda de sua caneta, trazendo involuntariamente parte do verso para a superfície de leitura. Como se houvesse direcionado um tiro inequívoco em toda a sua potência explosiva, preserva as páginas manuscritas muito próximas às do texto datilografado, com uma quantidade pequena de rasuras, mantendo uma disposição espacial bastante semelhante nas duas versões. Tudo leva a crer que Oiticica desenvolveu sua escrita como um arroubo contínuo, saído fulminante, como um jato que não podia ser interrompido, fruto de sua intensa relação com a cocaína naquele momento.

Nessas páginas de texto corrido, Oiticica não apenas apresenta a concepção das Cosmococas, como também adota, dentro de seu estilo particular, um tom ensaístico, ao se instalar no terreno intermediário entre o ético e o estético. Segundo Max Bense, o ensaio é uma tentativa, é quando o ato de escrever se reveste de um caráter de experimento, uma "expressão do modo experimental de pensar e agir" (BENSE, 2014). Neste caso, algumas páginas e trechos foram dedicados a uma construção de pensamento do projeto, que funciona especialmente como uma descarga sobre as suas inquietações. É então que, em meio a diferentes assuntos, o cinema surge com destaque, sobretudo na forma de posicionamentos críticos à imagem e ao cinema- 
espetáculo, no que parece ser uma gradativa consolidação de sua condição como pensador e realizador cinematográfico.

Mangue-Bangue (1971), marco da contracultura dirigido por Neville d'Almeida, protagoniza trechos importantes desse ensaio, tanto por sua temática transgressora, com um retrato cru de sexo e drogas em tempos de ditadura, mas principalmente por sua forma, editada em blocos e sem qualquer roteiro definido. Para Oiticica, o filme cria uma linguagem-limite, misturando sensualidade pictórica e a fragmentação em blocos, "como se fora um longo strip feito sequência tirado de estória em quadrinhos". É a partir dessa obra que o artista, que "q não sentia a menor tesão em 'montar' os takes q fizera para diversos projetos", junta-se a Neville para disparar o projeto das Cosmococas, propondo uma tentativa de reinvenção da "linguagemcinema", a partir da "fragmentação do cinetismo". ${ }^{10}$

jamais teria a necessidade de inventar esse tipo de experiência não fossem as longas conversas e caminhadas pela linguagem limite criada por MANGUE-BANGUE de NEVILLE: na verdade esses BLOCOS-EXP. são uma espécie de quase-cinema: um avanço estrutural na obra de NEVILLE e aventura incrível no meu afã de INVENTARde não me contentar com a 'linguagem-cinema' e de me inquietar com a relação (principalmente visual) espectador-espetáculo (mantida pelo cinema - desintegrada pela TV) e a não-ventilação de tais discussões: uma espécie de quietismo quiescente na crença (ou nem isso) da imutabilidade da relação: mas a hipnotizante submissão do espectador frente à tela de super-definição visual e absoluta sempre me pareceu prolongar-se demais: era sempre a mesma coisa:

(OITICICA, 0301/74, p. 2)

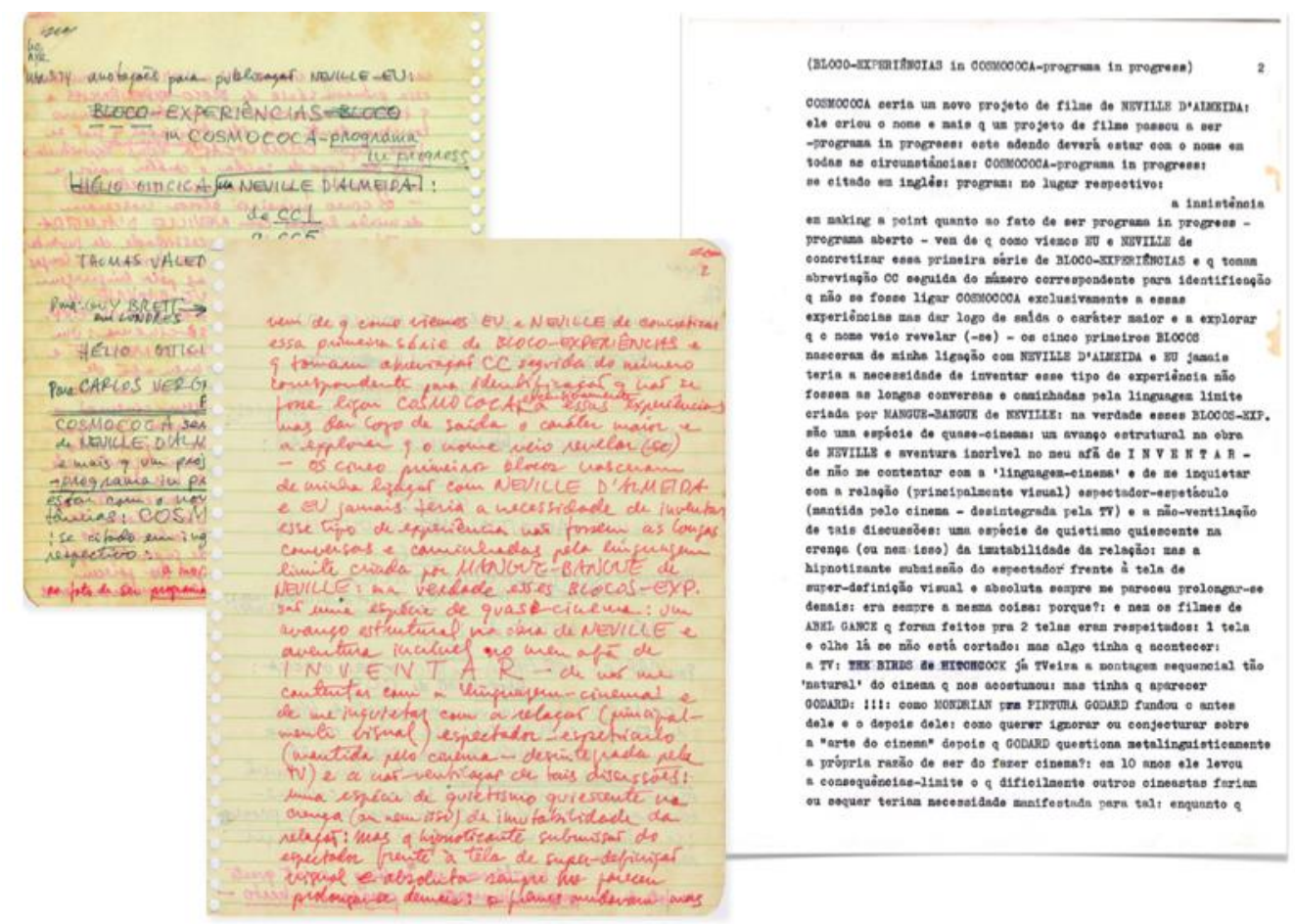

O cinema torna-se um dos grandes temas de Oiticica nas páginas dos cadernos de Cosmococas

${ }^{10}$ Todas as citações deste parágrafo foram retiradas de OITICICA, 0301/74, p. 2.

Revista Escrita

Rua Marquês de São Vicente, 225 Gávea/RJ CEP 22451-900 Brasil

Ano 2017. Número 23. ISSN 1679-6888.

escrita@puc-rio.br 
Num vai-e-vem temático, em que as frases passam rapidamente de um assunto a outro, Oiticica menciona pontualmente cineastas que contribuem para a construção de sua relação com o cinema, entre eles Abel Gance ("nem os filmes de ABEL GANCE q foram feitos pra 2 telas eram respeitados") 11, Jack Smith ("com seus slides fez algo q muito tem a ver com o q almejo com isso: do seu cinema extraiu - em vez de visão naturalista imitativa da aparência - um sentido de não-fluir não-narrativo" ${ }^{12}$ e, especialmente, Godard, comparado a Mondrian e apontado como um divisor de águas no cinema ("dissecou a linguagem-cinema com tanta posta em cheque e multivalência só comparáveis aos fenômenos TV e ROCK"13 / "ao contrário do romântico naturalista q se volta ao q chamam cinema verité [como se cinema fosse ficção!] penetra todos os meandros possíveis do cinema: joyful pela libertação gradativa do espectador numbeizado por absolutismos de linguagem e imagem" ${ }^{14}$ ). Ainda que com propostas muito diferentes, os três cineastas mencionados por Oiticica apresentavam posturas resistentes com relação ao cinema-espetáculo, seja pela quebra da narrativa, pela fragmentação das telas e quadros ou pela provocação à posição contemplativa dos espectadores. Nesse sentido de fluxo, também mistura McLuhan, TV, Stalin, MacCarthy, Hitler, Marilyn Monroe e os Beatles, sugerindo que todas as tentativas de dar unicidade à imagem, baseando-se na imutabilidade do espectador e na falta de improvisação, foram frustradas pela fragmentação da realidade.

Como estrangeiro de seu país, já que nesse momento vivia em Nova York, Oiticica aproveita também para alfinetar o cinema brasileiro, fazendo duras críticas ao que ele considerava uma carência de experimentalismo, voltada para a criação de uma indústria cinematográfica, e uma excessiva seriedade ("sempre a carroça na frente dos bois: excessivo concern: muita busca!: sem joy: sem COCA"15).

\section{Texto-roteiro: ideas for a scriptotal}

Em uma parte dos manuscritos, um estado indomesticável parece ter guiado a atividade do escritor, com rasuras frequentes e marcas de inclusão de novos trechos, a partir do uso de canetas de diferentes cores e do minucioso reaproveitamento dos espaços vazios do papel. É nessas páginas que Oiticica cria os roteiros específicos para a montagem de cada um dos blocos-experiências de Cosmococas.

No cinema, o roteiro exerce a dupla função de encadear o eixo narrativo de um projeto e de atuar como instrutor e articulador de processos como encenação, cenografia, sonoplastia, montagem, produção e direção. A palavra roteiro ressalta a característica dessa forma textual como uma condutora de ações e atividades, a partir de determinados campos fixos, onde se encontram a indicação da locação e do horário da cena (dia ou noite), uma descrição de ações, os nomes dos personagens e os

\footnotetext{
${ }^{11}$ OITICICA, 0301/74, p. 2.

${ }^{12}$ OITICICA, 0301/74, p. 8.

${ }^{13}$ OITICICA, 0301/74, p. 3.

${ }^{14}$ OITICICA, 0301/74, p. 3.

${ }^{15}$ OITICICA, 0301/74, p. 3.
} 
diálogos. Para Jean-Claude Carrière (2004, p. 100), o roteiro é um texto em mutação, de passagem, em que as palavras são geradoras de imagens e sons. Assim como num roteiro convencional, encontram-se nesses textos cabeçalhos com informações sobre a obra, o número do bloco-experiência e seu título, além de indicações específicas para a montagem, com data, local e hora do dia, marcações sobre a disposição dos projetores, a sequência dos slides e a trilha sonora. Oiticica, no entanto, intenciona ultrapassar em muito a geração de imagens e sons. É no uso de adereços e objetos no ambiente e, especialmente, no tipo de interação proposta aos participantes que se apresenta um outro tipo de roteiro ${ }^{16}$, impregnado pela vontade de potencializar a palavra e a disposição espacial (texto-poema), assim como de construir, ensaiar e experimentar uma forma de cinema (texto-ensaio). Como numa espécie de manifesto, esses textos apresentam uma preocupação estética, representada pelo cuidado com a diagramação e a escolha de palavras, e um caráter imperativo, que mistura a necessidade de instruir a montagem, mas também de construir um ponto de vista. Mais do que induzir a ação e reflexão, o texto aqui tem a função de mobilizar, provocar e disparar novas relações com o uso da imagem, do som, do ambiente e da interação com objetos e adereços.

Para a performance pública de CC2 Onobject (ou Yoko Mask), por exemplo, Oiticica convida os "participadores" a entrarem num ambiente com o piso coberto de espuma branca, projeções em duas paredes e uma trilha sonora formada por gritos de Yoko Ono. Eles são convidados a interagir com formas geométricas em espuma, a partir de uma sugestão para a indução de um jogo que provoque um estado de dança e movimento durante a projeção. Para a performance privada, estavam previstos quatro conjuntos de slides a serem projetados simultaneamente, de acordo com tempo e sequência discriminados, em superfícies a serem improvisadas de acordo com o local. A ordem é: IMPROVISAR e PROJETAR.
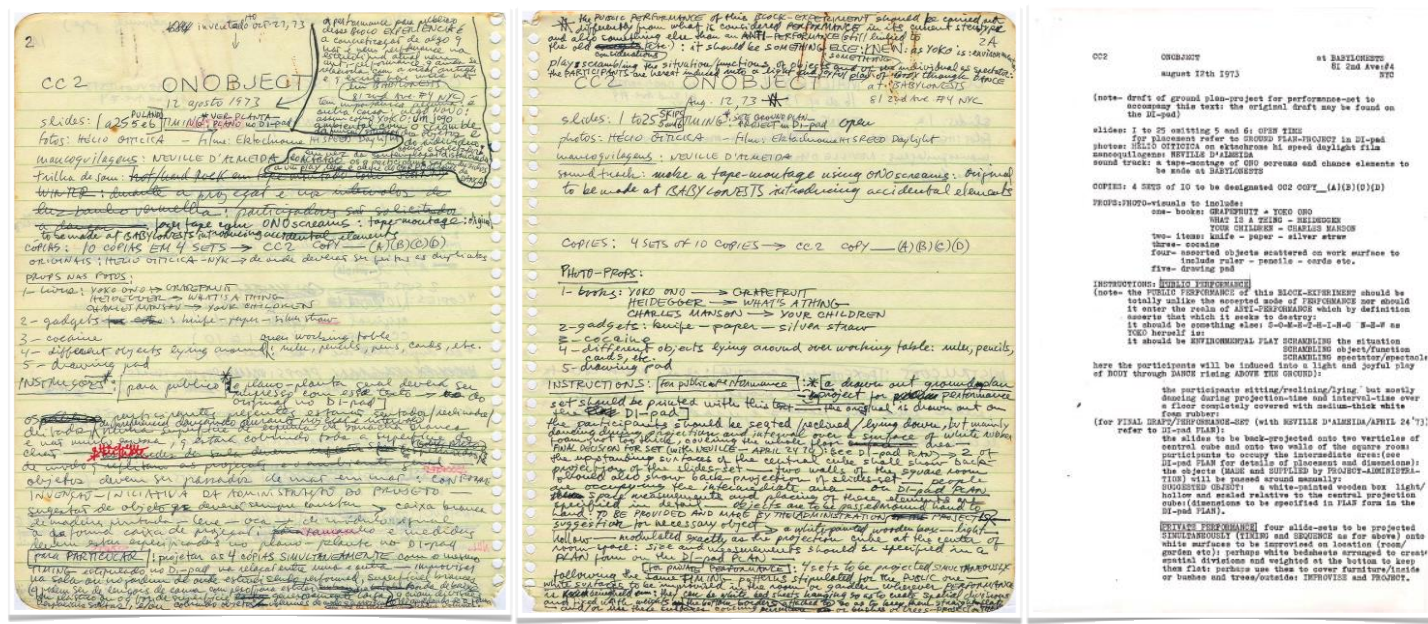

16 Steven Price (2013, p. 236-237) propõe uma interessante observação sobre o roteiro de cinema, apontando que, tanto no roteiro industrial como nas suas formas mais pessoais, mantém-se sempre o formato de uma escrita modular, que opera por meio de fragmentos e blocos. Dentro desse sentido mais abrangente, uma parte do texto de Oiticica poderia ser considerada um "roteiro de cinema", desde que se adote uma definição mais elástica de ambos os termos ("roteiro" e "cinema"). 


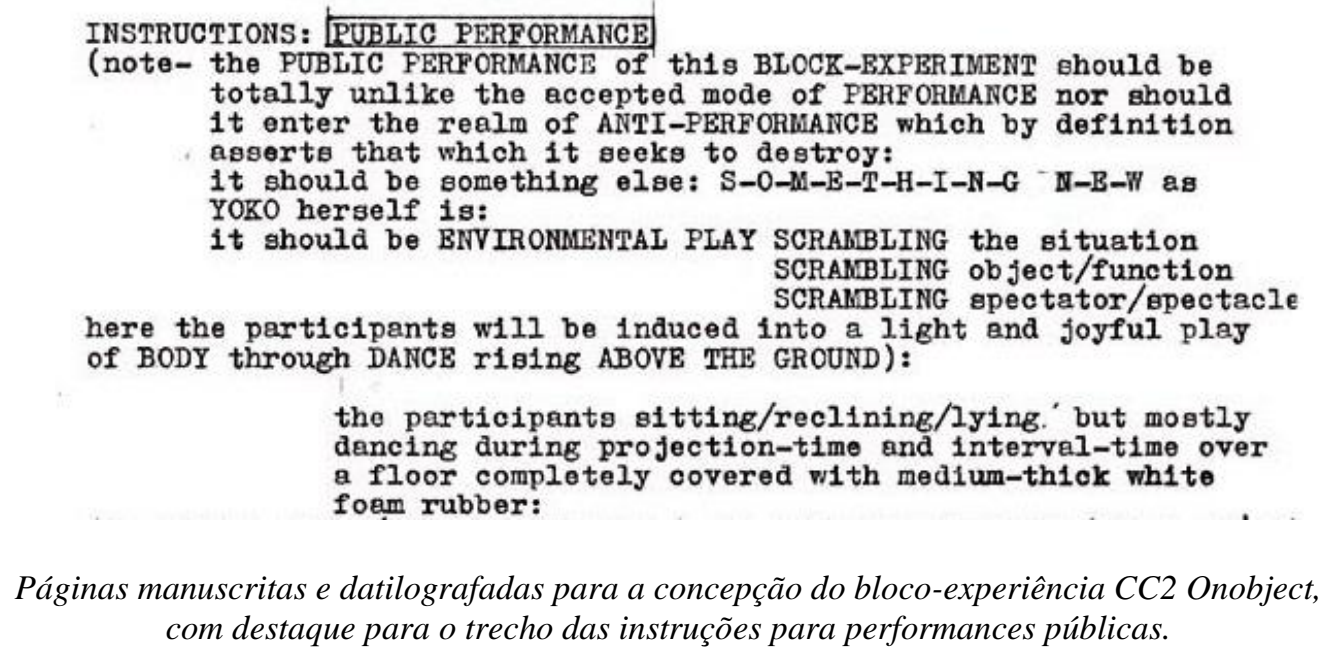

\section{Quasi-cinema?}

O projeto de quasi-cinemas, de Hélio Oiticica e Neville d'Almeida, entre os quais se encontram as Cosmococas, funda-se a partir de um prefixo que significa como ou do mesmo modo que e pressupõe uma semelhança, um parentesco, mas jamais uma ideia de inserção integral. Como lembra Kátia Maciel (2009), os quasi-cinemas foram além do cinema, ultrapassando a arquitetura do teatro italiano e o sistema de projeção que alocava o espectador em um ponto fixo. Nesse sentido, num momento em que se desenvolvia uma forte ampliação da ideia de cinema, é interessante observar que, embora tenha adotado uma postura tímida, ao se nomear como quasi, o projeto não por acaso é reconhecido com uma importante referência mundial do cinema expandido.

Nos anos 50 e 60, com a ampliação da permeabilidade entre linguagens, a ideia de cinema espalha-se pelas criações de artistas visuais, tensionando os limites do cinema hegemônico de maneiras bastante diversas: enquanto alguns artistas propunham novos discursos e se insurgiam contra a narratividade, outros buscavam ampliar as formas de consciência, procurando na experiência cinematográfica vias para exercitar os estímulos sensoriais. No pós-Segunda Guerra, quando o eixo central da arte deslocou-se de Paris para Nova York - justamente no momento em que Oiticica vivia na cidade e concebia o projeto de quasi-cinemas -, trabalhar o cinematográfico no campo da arte tornou-se um processo mais ousado e recorrente. Peter Weibel (2003) aponta que, embora cineastas como Andy Warhol, Guy Debord e Yoko Ono fossem ligados a movimentos ou grupos de arte, como a Pop Art, o Situacionismo Internacional e o Fluxus, o cinema independente ou experimental já não era mais um subproduto das 
artes visuais, como nas vanguardas dos anos 20 e 30, e sim um campo que reclamava seu protagonismo. É nessa década que o código cinematográfico foi atravessado pelo que o autor chama de "uma subversão explosiva", com experimentações que passaram por uma vasta gama de possibilidades, formando um universo heterogêneo, em que coexistiam obras e projetos que investigavam materiais, múltiplas telas, narrativas, tempo e espaço, questões sociais e sexuais, som, entre outras possibilidades de ampliação do cinemático. O celuloide foi então arranhado, perfurado, coberto de marcas, pintado, superexposto; a câmera e o projetor foram desmontados, remontados e reinventados; as câmeras perderam seus filmes; cortinas de fumaça, água e corpos humanos foram usados como superfície de projeção; a tela tornou-se múltipla e móvel, curva, pontiaguda, substituída por materiais como água, madeira e edifícios; as narrativas ganharam múltiplas perspectivas, combinando diferentes abordagens e técnicas de montagem; o espectador passou a integrar a obra como personagem ativo; o tempo fílmico foi estendido, retardado, abreviado; as esferas mais íntimas e individuais passaram a constituir o repertório das obras; as imagens e sons encontrados ao acaso tornaram-se elementos de criação; sons artesanais e dissonantes de toda a ordem invadiram os projetos.

Dentro desse amplo universo surgiu o conceito de grande latitude "cinema expandido", que procurava abarcar variados tipos de manifestação. Surgido no manifesto "Culture: intercom and expanded cinema, a proposal and manifest" (1965), de Stan VanDerBeek, o termo, que hoje se reinventa especialmente na relação com o digital, traduzia naquele momento a ideia de um cinema disposto a propor formulações que superassem a tela única e tipo de espectador do cinema convencional. Para Gene Youngblood, o crítico norte-americano que popularizou o termo no livro Expanded Cinema (1970), o cinema expandido estava relacionado a uma consciência expandida, a um impulso histórico e contínuo do homem de manifestar a sua consciência fora da sua mente, a uma vida que se tornaria arte. ${ }^{17}$ A pesquisadora Victa de Carvalho (2008) destaca também a relação desse tipo de cinema com a utopia de uma arte total, o que se manifestou pela combinação de elementos de cinema, teatro, fotografia e música, com a realização de espetáculos únicos e com duração própria, na forma de happenings e performances, em que se valorizavam improvisos e acasos, em especial a partir da

\footnotetext{
${ }^{17}$ Enquanto outros autores buscam uma maior diversidade de manifestações na definição do termo "cinema expandido", Youngblood volta-se sobretudo para os cinemas sinestésico, cibernético e holográfico, que incluem a experimentação com as tecnologias de vídeo e informática. 
questão do corpo e da presença. Outro ponto importante era a problematização da narrativa, da técnica de projeção e da tela de exibição, com a revelação do projetor como parte da obra, as propostas que se constituíam por multiprojeções ou obras que apostavam na dissolução da própria tela. É nesse contexto que surgem experiências pioneiras, como o Movie-Drome, Movie Movie e Corpocinema ${ }^{18}$, que reuniam muitas dessas características, provocando a posição do espectador e trazendo diferentes possibilidades para as telas de exibição e a forma de projeção.

Cosmococas também foi um projeto que investigou as possibilidades da experiência cinematográfica em pensamento e realização, tangenciando alguns pontos centrais do cinema expandido. As mesmas preocupações que estimularam a produção das manifestações reunidas sob essa alcunha - com as quais Oiticica entrava em contato na estimulante atmosfera nova-iorquina da década de 70 - apresentam-se em sua obra, de maneira primordial, por meio da escrita. É nos textos que se desvelam os elementos mais essenciais desse cinema expandido, como a questão do espectador ("libertação gradativa do espectador numbeizado"19), do acaso ("num lance de dados e nunca como fixação em modelos" ${ }^{20}$ ), da não-narrativa ("em vez de visão naturalista imitativa da aparência - um sentido de não-fluir não-narrativo" ${ }^{21}$ ), da projeção ("enquadrar a projeção em paredes-teto-chão" ${ }^{22}$ ), da tela de exibição ("2 telas" ${ }^{23}$ ), do ambiente ("pensei em princípio no AMBIENTE FRAGMENTADO"24), da arte total ("TODOPERFORMANCE" 25) e até mesmo da consciência expandida ("a PRESENÇA DA

\footnotetext{
${ }^{18}$ Realizado de 1963 a 1965 em Nova York, por Stan VanDerBeek, o Movie-Drome era uma cúpula geodésica, que no seu interior funcionava como uma superfície para uma multiprojeção com imagens em $16 \mathrm{~mm}, 35 \mathrm{~mm}$ e slides, a partir de colagens aleatórias que rodavam em loop. O chão, forrado com almofadas, permitia que os espectadores assistissem às projeções deitados. Movie Movie (1967), uma parceria de Jeffrey Shaw, Theo Botschuijer, Tjebbe van Tijen e Sean Wellesley-Miller, trazia imagens cinematográficas projetadas sobre uma estrutura inflada em forma de cone, usando vários projetores e líquidos luminosos, que modificavam as imagens da tela a partir de manipulações dos espectadores. Já Corpocinema (1967), também de Jeffrey Shaw, consistiu de uma série de performances ao ar livre, em Roterdã e Amsterdam, em que eram projetados filmes e slides em uma cúpula inflável, com performances e música ao vivo. Uma importante característica da obra foi transformar a superfície de projeção em um espaço de interação física e material, em que os artistas e participantes eram convidados a pintar e fazer colagens diretamente na cúpula, como forma de explorar as possibilidades de efeito com as imagens projetadas.

${ }_{19}$ OITICICA, 0301/74, p. 3.

${ }^{20}$ OITICICA, 0301/74, p. 11.

${ }^{21}$ OITICICA, 0301/74, p. 8.

${ }^{22}$ OITICICA, 0301/74, p. 8.

${ }^{23}$ OITICICA, 0301/74, p. 2.

${ }^{24}$ OITICICA, 0301/74, p. 15.

${ }^{25}$ OITICICA, 0301/74, p. 16.
} 
COCAÍNA como elemento-prop"26).

\section{Glossário das Cosmococas: cinema e escrita em expansão}

Além dos elementos de destaque (como boxes, negritos, letras maiúsculas e setas), a escrita retorcida de Oiticica destaca-se sobretudo pelo que Frederico Coelho (2008, p. 25) classifica como "palavras-conceitos". De modo geral grafadas em letras maiúsculas, como se fossem etiquetas, essas palavras-conceitos, que também podem ser expressões-conceitos, provocam a eclosão de referências centrais sobre seu processo de criação e reflexão, tal como pontos concentrados, capazes de atuar metonimicamente diante de toda a sua dilatada escrita.

Para demonstrar visualmente a abundância de palavras-conceitos criadas por Oiticica, selecionei todas as suas recorrências, ao longo das páginas datilografadas de Cosmococas, em inglês e português, e desse material construí, com a ajuda do gerador Wordle $^{27}$, uma nuvem de tags. Essa ferramenta, comumente utilizada para catalogar e facilitar o acesso a determinados temas dentro de websites, permite entrar em contato com a grandiosa escala de portas de entrada provocadas pela escrita de Oiticica no universo das Cosmococas:

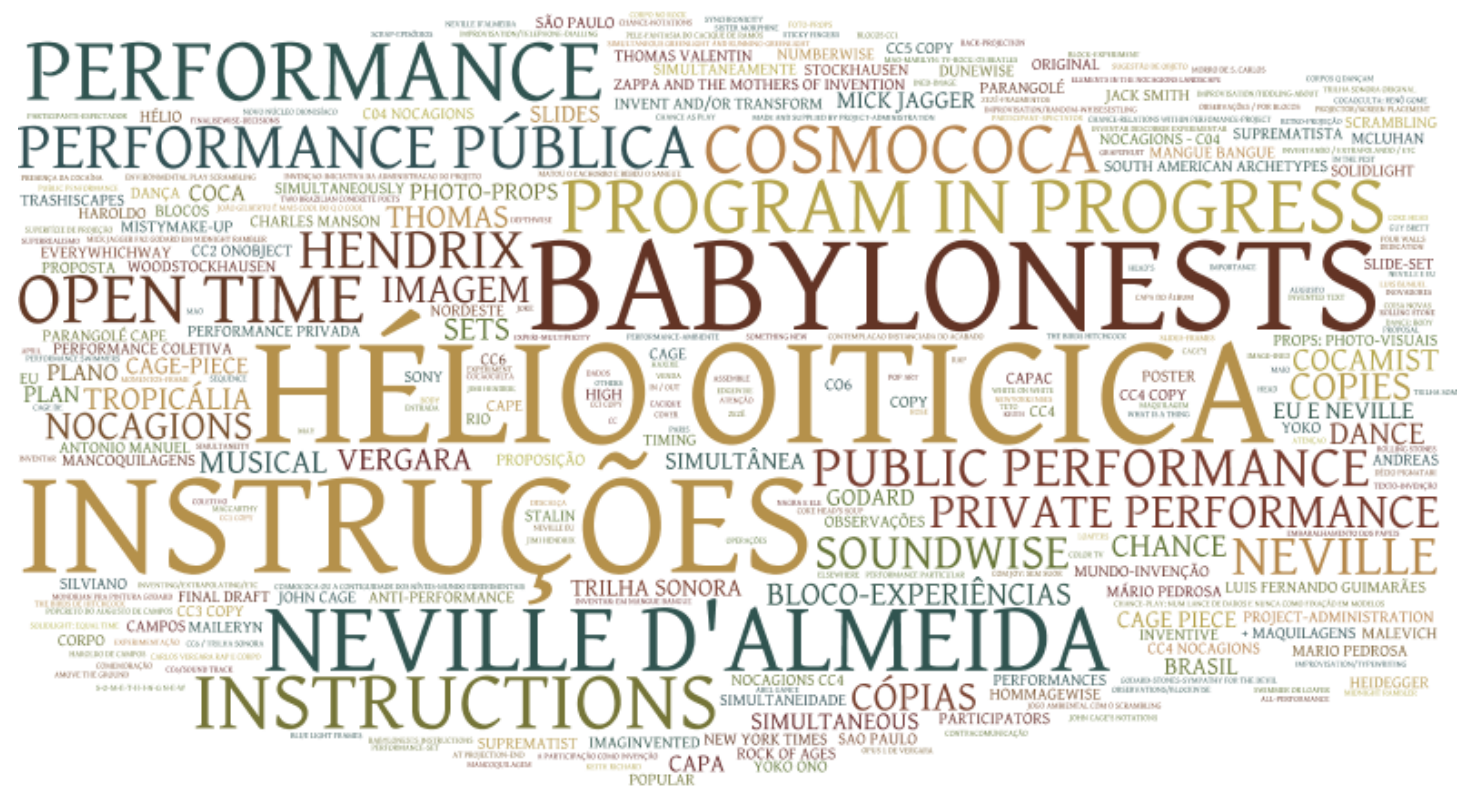

Nuvem de tags feita a partir de palavras e expressões em destaque dos cadernos das Cosmococas

\footnotetext{
${ }^{26}$ OITICICA, 0301/74, p. 9.

${ }^{27}$ Disponível em www.wordle.net.
} 
A hierarquização das nuvens de tag, a partir de uma maior ou menor incidência das palavras listadas, ajuda a identificar os termos mais usados por Oiticica nos dois cadernos em que gestou as Cosmococas. É curioso notar o grande destaque com que aparecem nomes (do próprio artista, de seu parceiro nos quasi-cinemas, das Babylonests $^{28}$ e das Cosmococas - Program in progress), o que pode ser explicado em parte pelos cabeçalhos das páginas, que identificavam a obra, os autores e o lugar onde foram criadas. Outra palavra em evidência é "performance", que nos textos aparece de diferentes maneiras (JOGOS-PERFORMANCE, PERFORMANCE-AMBIENTE, PERFORMANCE-PROJEÇÃO) e orienta a montagem das performances públicas e privadas. $\mathrm{O}$ uso recorrente desse termo por Oiticica relaciona-se com o que Érika Fischer-Lichte (2011, p. 37) classificou como "virada performativa", para resumir o momento de estreita relação com que as artes ocidentais aproximaram-se da arte da ação e da performance, distendendo suas fronteiras e voltando-se cada vez mais à criação de acontecimentos. Mas o que chama de fato a atenção na imagem é a dimensão da palavra "instruções", o termo adotado como forma de delimitar as suas experiências-jogos, funcionando como o cerne dos blocos-experiências. Seguindo o tipo de proposta desenvolvido por Yoko Ono e o Fluxus ${ }^{29}$, Oiticica aposta nas instruções como possibilidade de abertura ao acontecimento. Apenas mediante o condicionamento das regras o participador poderia efetivamente aderir às propostas dos blocos-experiências.

(...) vem as INSTRUÇÕES q se dirigem às PERFORMANCES particulares com pouca gente (indoors ou outdoors) e às PERFORMANCES públicas q visam experiênciasjogos de grupos: seguir as INSTRUÇÕES e abrir-se ao jogo e à experiência participatória q e a razão de ser das CC: ignorar as INSTRUÇÕES e fechar-se e não participar da experiência: qual e?: (OITICICA, 0301/74, p. 9)

Ainda que o método de incidência de termos provoque a irresistível tentação de analisar esses conceitos sob essa ótica, esse tipo de ferramenta cria desvios e a necessidade de uma leitura mais atenta. "Performance" e "performance pública", por exemplo, são discriminados na nuvem, gerando palavras com menos intensidade. Além disso, enquanto um termo como "Babylonests" aparece com relevância, apenas por identificar o local de escrita dos textos, outros como "mancoquilagem", essenciais para a concepção do projeto, apresentam-se em tamanho bastante reduzido. Por esse motivo, adotei aqui outro critério de análise, para complementar a nuvem de tags, a partir da capacidade de reverberação de cada um desses termos. A pergunta que norteou esta seleção foi: dentro dos textos datilografados das Cosmococas, quais foram as palavras, termos e expressões lançados como "projeções, explosões, vibrações, maquinarias,

\footnotetext{
${ }^{28}$ Oiticica construiu, em seu primeiro loft em Nova York, ninhos dentro dos quais vivia, aos quais chamou de Babylonests e onde moravam diversas outras pessoas.

${ }^{29}$ Além de homenagear Ono nas CC2, Oiticica cita nas Cosmococas obras como Mask Piece 2 (1964), em que a artista provocava os participantes a partir de instruções ao mesmo tempo rigorosas e irônicas: "Faça máscara menor q a sua cara. Deixe q ela beba vinho em vez de você" (ONO apud OITICICA, OITICICA, 0301/74, p. 11).
} 
sabores" ${ }^{30}$ para um cinema expandido? Cheguei a um resultado de 22 itens, dentro de tudo o que foi destacado por Oiticica com letras maiúsculas, formando uma espécie de glossário de termos capazes de atuar como uma apresentação do seu projeto de cinema expandido, condensando algumas de suas principais diretrizes. ${ }^{31}$

\section{Glossário Cosmococas}

\author{
1. (CORPO!) \\ 2. AMBIENTE FRAGMENTADO \\ 3. ASSEMBLE \\ 4. BLOCOS-EXPERIÊNCIAS \\ 5. CHANCE AS PLAY \\ 6. CÓPIA \\ 7. ESPETÁCULO \\ 8. IMAGEM \\ 9. IMPROVISATION \\ 10. INSTRUÇÕES \\ 11. INVENÇÃO-MUNDO
}

\author{
12. PERFORMANCE \\ 13. JOGO AMBIENTAL \\ 14. JOY \\ 15. MOMENTOS-FRAME \\ 16. NÃONARRAÇÃO \\ 17. S-O-M-E-T-H-I-N-G N-E-W \\ 18. SCRAMBLING \\ 19. SEQUÊNCIA \\ 20. SIMULTANEIDADE \\ 21. SINCRONICIDADE \\ 22. TRILHA SONORA
}

\footnotetext{
${ }^{30}$ Esse trecho refere-se especificamente a uma parte de Aula, quando Barthes contesta a oposição entre o discurso da ciência (especialmente da linguística), segundo o qual o saber é um enunciado, e o da escritura, o terreno da enunciação, onde o sujeito é de fato exposto. É neste último tipo de escritura que "as palavras não são mais concebidas ilusoriamente como simples instrumentos, são lançadas como projeções, explosões, vibrações, maquinarias, sabores: a escritura faz do saber uma festa". (BARTHES, 2009 , p. 19) Por outro lado, Barthes propõe uma aproximação de procedimentos entre cientistas e escritores, sugerindo, na célebre passagem, que a escritura encontra-se "em toda parte onde as palavras têm sabor (saber e sabor têm, em latim, a mesma etimologia)". (BARTHES, 2009, p. 19)

${ }^{31}$ As grafias dos termos, incluindo as pontuações, foram mantidas de acordo com o original.
} 
Embora alguns desses termos tenham sido amplamente investigados por outros pesquisadores nos diferentes momentos da obra de Oiticica, como "play" e "performance", aqui eles serão tratados dentro do restrito universo das Cosmococas, especialmente na maneira como se relacionam com uma ideia de cinema expandido. Mais do que redundar nas discussões anteriormente iniciadas, estes 22 itens funcionam como um encerramento que intenciona sintetizar a elaboração extremamente fecunda desse projeto, mas especialmente acionar o convite ao recomeço de novas reflexões e manifestações sobre a escrita e o cinema, a partir de algumas pontuações finais.

Dentro do glossário, alguns termos delimitam as bases centrais para a montagem das Cosmococas: BLOCOS-EXPERIÊNCIAS, IMAGEM, TRILHA SONORA, PERFORMANCE, INSTRUÇÕES, MANCOQUILAGENS. Como corpo que só existe de modo integrado, os elementos aqui combinam determinados recursos usuais nos cinemas expandidos (IMAGEM, TRILHA SONORA, INSTRUÇÕES, PERFORMANCE) e invenções em termos conceituais e técnicos (BLOCOSEXPERIÊNCIAS e MANCOQUILAGENS), que se tornaram ingredientes fundamentais do projeto de Oiticica e Neville D'Almeida.

O glossário inclui também termos que, combinados, reforçam determinados conceitos estruturantes na concepção do projeto. O primeiro deles é a ideia de fragmento, que está presente tanto na noção mais ampla que expõe o conceito e a espacialidade das obras (AMBIENTE FRAGMENTADO e BLOCOSEXPERIÊNCIAS) como no caráter mais pontual e crítico que procura romper com a narratividade do cinema convencional, na forma de MOMENTOS-FRAME. Oiticica também exalta o caráter festivo das Cosmococas a partir de um corpo exclamativo, alegre e brincante (CORPO!, JOY e CHANCE AS PLAY) e acentua a importância do acaso e do jogo (JOGO AMBIENTAL, CHANCE AS PLAY) como estratégia de criação das suas regras. Finalmente, o artista combina, monta, mistura, mexe e liquidifica todos esses elementos (ASSEMBLE e SCRAMBLING).

Esse desejo de embaralhar está presente especialmente nos termos do glossário que sugerem um sentido de contraste. Em termos de procedimento, por exemplo, as regradas INSTRUÇÕES são responsáveis pelo estímulo à IMPROVISAÇÃO. Da mesma forma, a ideia de inventividade não discrimina a cópia do novo (S-O-M-E-T-HI-N-G N-E-W e CÓPIA) ou a parte do todo (INVENÇÃO-MUNDO/MUNDOINVENÇÃO e AMBIENTE FRAGMENTADO), trazendo consigo diferentes temporalidades (SEQUÊNCIA e SIMULTANEIDADE), além de uma concepção de cinema que se afasta da linearidade (NÃONARRAÇÃO), sem abrir mão do arrebatamento da experiência (ESPETÁCULO).

A observação mais atenta desses termos, portanto, não apenas confirma a relação das Cosmococas com o cinema expandido (ultrapassando a ideia do quasicinema), mas também o tipo de cinema expandido que Oiticica projetava, a partir de uma paradoxal ruptura de inclusão, que questionava o cinema convencional, incorporando o espetáculo, o prazer, o mundo, o fragmento, o something new e a cópia, o acaso e a instrução. E é dessa relação entre cinema e escrita, dessa mútua nutrição de 
procedimentos, de uma ideia de texto-montagem ${ }^{32}$, que a atuação transbordante de Oiticica encontra substrato para se reconstruir e antecipar discussões contemporâneas sobre a expansão desses campos.

\section{Referências}

BARTHES, Roland. Aula. Tradução: Leyla Perrone-Moisés. 14ª edição. São Paulo: Cultrix, 2009.

BENSE, Max. "O ensaio e sua prosa”. Tradução: Samuel Titan Jr. In: Revista Serrote, n.16. São Paulo: Instituto Moreira Salles, 2014, p. 169-183. Disponível em http://www.revistaserrote.com.br/2014/04/o-ensaio-e-sua-prosa/.

BRAGA, Paula. A trama da terra que treme: multiplicidade em Hélio Oiticica. 2007. 209 f. Tese (Doctorate in Philosophy) - Faculdade de Filosofia, Letras e Ciências Humanas da Universidade de São Paulo, São Paulo. 2007.

CARRIÈRE, Jean-Claude. "Reflexões de um roteirista". Tradução: Ignácio Dotto Neto. Revista Contracampo, n.10-11, 2004. Disponível em www.uff.br/contracampo/index.php/revista/article/ download/531/278. Último acesso em 22 nov. 2014.

CARVALHO, Victa de. O Dispositivo na Arte Contemporânea: relações entre cinema, vídeo e mídias digitais. 184 f. Tese (Doutorado em Comunicação e Cultura) Escola de Comunicação/UFRJ. 2008.

COELHO, Frederico. Livro ou livro-me: os escritos babilônicos de Hélio Oiticica (1971-1978). 295 f. Tese (Letras) - PUC-Rio. 2008.

COMPAGNON, Antoine. O trabalho da citação. Tradução: Cleonice Mourão. Belo Horizonte: UFMG, 2007.

FISCHER-LICHTE, Erika. Estética de lo performativo. Madrid: Abada, 2011.

MACIEL, Katia. "O cinema tem que virar instrumento": As experiências quasi-cinema de Hélio Oiticica e Neville de Almeida. In: MACIEL, Katia (org.), Transcinemas. Rio de Janeiro: Contra Capa, 2009, p. 281-292.

OITICICA, Hélio.Bloco experiência in COSMOCOCA - programa in progress. Tombos: 0299/73, 0300/73, 0308/73, 0301/74.

PERLOFF, Marjorie. O gênio não original: poesia por outros meios no novo século. Tradução: Adriano Scandolara. Belo Horizonte: UFMG, 2013.

PRICE, Steven. A history of the screenplay. Hampshire: Palgrave Macmillian, 2013.

\footnotetext{
${ }^{32}$ Segundo Frederico Coelho (2008, p. 151), Oiticica trabalha com a ideia de "montagem-linguagem" em sua escrita, a partir da qual "o fragmento em plena potência". Já Paula Braga (2007, p. 14) lembra que Oiticica usou o termo texto-montagem em carta a Lygia Clark, quando se referiu ao projeto de Newyorkaises. 
WEIBEL, Peter. Expanded Cinema, Video and Virtual Environments. In: Future Cinema: The Cinematic Imaginary after Film, eds. Jeffrey Shaw and Peter Weibel. Cambridge: MIT Press, 2003, p. 110-124.

YOUNGBLOOD, Gene. Expanded Cinema. New York: Dutton, 1970.

QUEIROZ, Beatriz. O cinema "além da arte" em "Nitrobenzol \& Black Linoleum", de Hélio Oiticica. $9^{\circ}$ Encontro Nacional de História da Mídia, Ufop, MG, 30 de maio a $1^{\mathrm{o}}$ de junho de 2013. Disponível em http://www.ufrgs.br/alcar/encontros-nacionais1/9o-encontro-2013/artigos/gt-historia-da-midia-audiovisual-e-visual/o-cinema201 calem-da-arte201d-em-201cnitrobenzol-black-linoleum201d-de-helio-oiticica. Último acesso em 24 abril 2016. 